\title{
Type I aortopulmonary window presenting with very early onset Eisenmenger's syndrome
}

\author{
Soumya Patra, Navin Agrawal, Jayaranganath Mahimarangaiah, \\ Cholenhally Nanjappa Manjunath
}

Department of Cardiology, Sri Jayadeva Institute of Cardiovascular Sciences \& Research, Bangalore, Karnataka, India

\section{Correspondence to}

Dr Navin Agrawal,

drnavinagrawal@gmail.com
CrossMark

To cite: Patra S, Agrawal N, Mahimarangaiah J, et al. BMJ Case Rep Published online: [please include Day Month Year] doi:10.1136/ bcr-2013-201492

\section{DESCRIPTION}

A 2-year-old child with a history of recurrent chest infection early in infancy presented with clubbing, cyanosis, oxygen saturation of $86 \%$ in room air, left parasternal heave, short ejection systolic murmur at left second space and loud pulmonary component of second heart sound suggestive of severe pulmonary hypertension.

X-ray revealed cardiomegaly with pulmonary artery dilation and peripheral vasoconstriction (figure 1). Echocardiography revealed biventricular hypertrophy with moderate tricuspid regurgitation and pulmonary artery systolic pressure of $90 \mathrm{~mm} \mathrm{Hg}$. A large aortopulmonary (AP) window $(1 \mathrm{~cm})$ was demonstrated in the parasternal short axis view with bidirectional shunting (figures 2-4, videos 1-3). Cardiac catheterisation to assess for the reversibility of the shunt revealed that there was

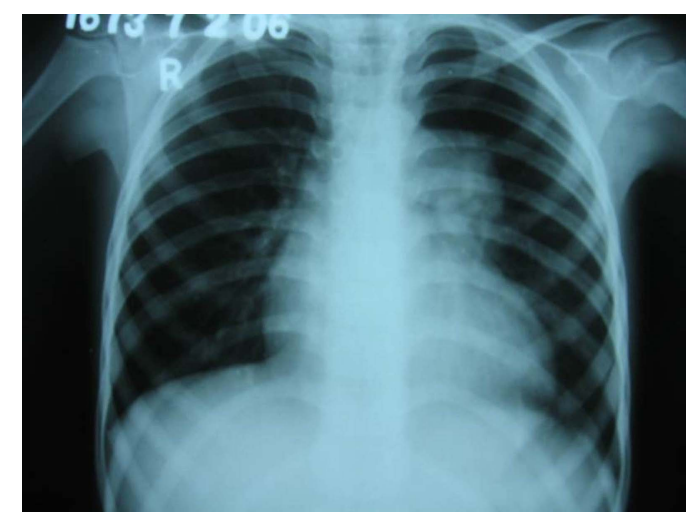

Figure $1 \quad X$-ray of the child showing cardiomegaly with pulmonary arteries showing peripheral vasoconstriction and dilation of the main pulmonary artery trunk and the central pulmonary arteries.

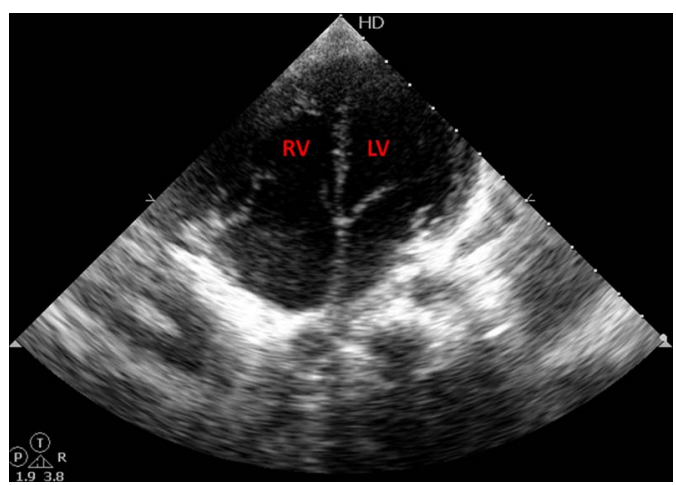

Figure 2 Apical 4-chamber view showing biventricular hypertrophy and biventricular dilation. LV, left ventricle; $\mathrm{RV}$, right ventricle.

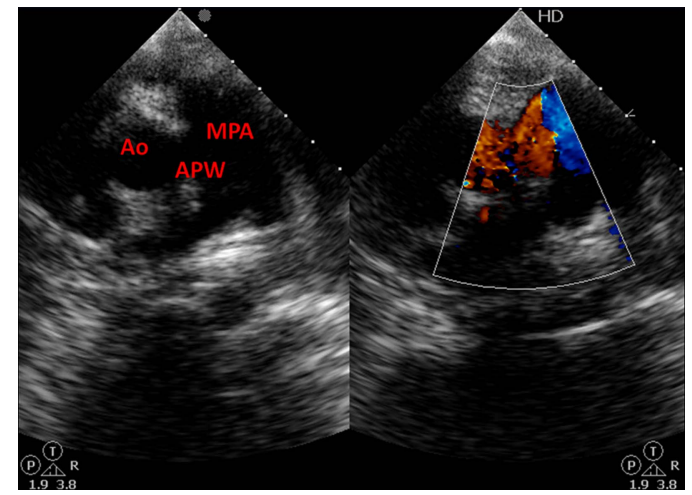

Figure 3 Parasternal short axis view with colour compare image show large aortopulmonary window (APW) between aorta (Ao) and main pulmonary artery (MPA) with bidirectional flow with predominant right to left shunt.

irreversible pulmonary hypertension, hence the child was managed medically with medications to decrease pulmonary arterial pressure like bosentan.

Aortopulmonary window is a rare disease with an incidence of $0.1 \%$ and is classified by Mori et al into three types. ${ }^{1}$ Type I, which is the most common type and seen in our case, is described as a defect midway between the semilunar valve and the pulmonary bifurcation. ${ }^{2}$ Echocardiography is the investigation of choice and can accurately diagnose and prognosticate the disease and cardiac catheterisation is usually required for ambiguity in diagnosis or for the assessment of shunt reversibility. ${ }^{3}$

Survival depends on the size of the defect and the pulmonary vascular resistance. In case of large defect, if left untreated, the majority of patients die in infancy with heart failure and only few survive

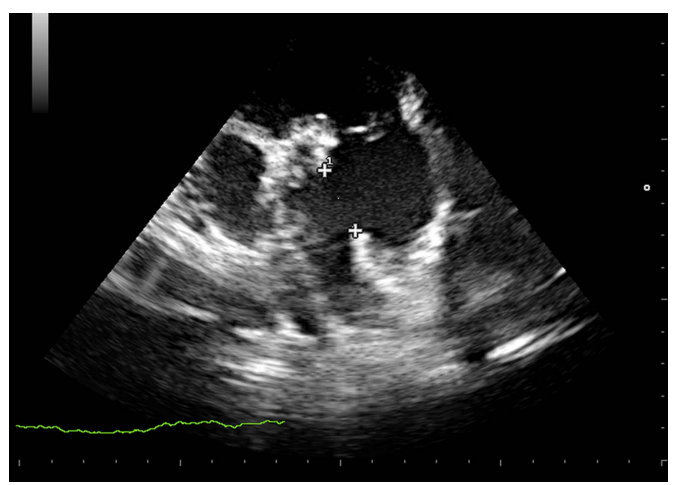

Figure 4 Modified parasternal short axis view showing the measurement of aortopulmonary window to be $1 \mathrm{~cm}$. 


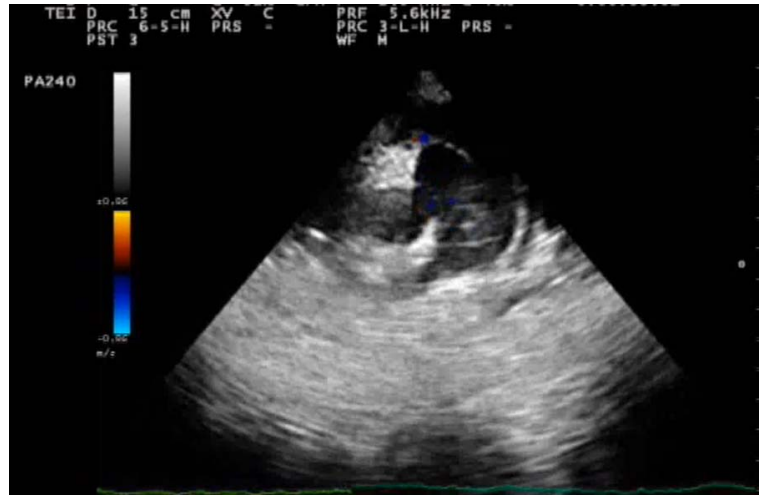

Video 1 Parasternal short axis view at the level of the aortic valve with colour doppler showing a large AP window with predominantly right to left shunt.

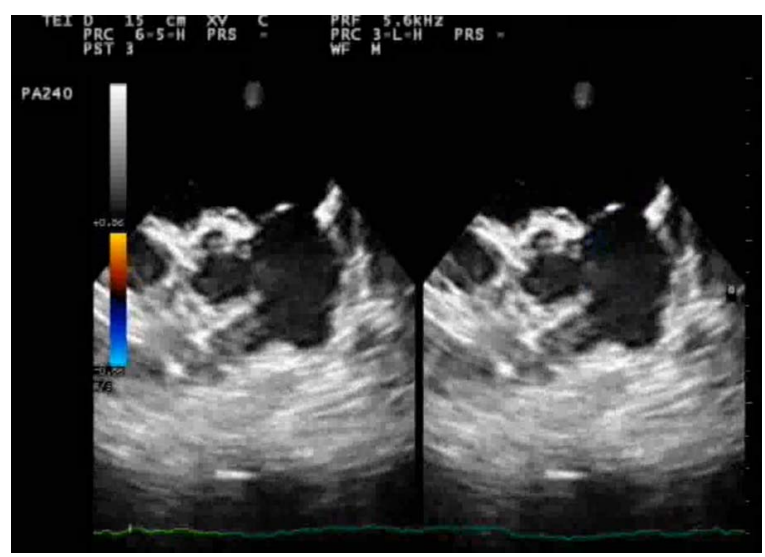

Video 2 Parasternal short axis view with colour Doppler showing laminar flow across the defect with a predominant right to left shunt in comparison to the same view without colour.

till adolescence or adulthood. Early closure of defect either surgically (preferred in most cases) or by device (small restrictive defect) is the treatment of choice and outcome after successful and early closure is excellent.

\section{Competing interests None.}

Patient consent Obtained.

Provenance and peer review Not commissioned; externally peer reviewed.

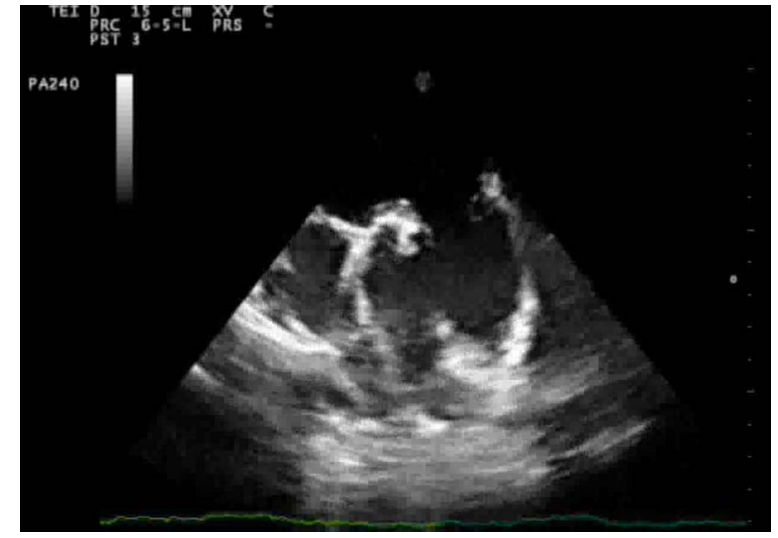

Video 3 Modified parasternal short axis view showing the aortopulmonary window between the aorta and the pulmonary artery.

\section{Learning points}

Aortopulmonary window is a rare congenital heart disease which predisposes to Eisenmenger's syndrome much earlier than other left to right shunts. A certain percentage of patients are prone to directly transform to Eisenmenger's without a preceding stage of heart failure due to large left to right shunt.

- The cases require early diagnosis preferably with the help of a careful echocardiogram in association with other clinical clues and easily available investigations like X-ray and pulse oximetry. Cardiac catheterisation could be performed preoperatively to assess for shunt reversibility.

- Early surgical (preferred) or device closure (if suitable) of this defect is recommended before development of the irreversible pulmonary vascular obstructive disease.

\section{REFERENCES}

1 Shamim AA, Khan MZ, Atiq MA, et al. Surgical correction of aortopulmonary window: a rare and lethal cause of pulmonary hypertension. J Pak Med Assoc 2011;61:836-8.

2 Tkebuchava T, von Segesser LK, Vogt PR, et al. Congenital aortopulumonary window: diagnosis, surgical technique and long-term results. Eur J Cardiothorac Surg 1997;11:293-7.

3 Apitz C, Kaulitz R, Sieverding L, et al. [Echocardiographic diagnosis of the aorto-pulmonary window]. Ultraschall Med 2007;28:189-94.

Copyright 2014 BMJ Publishing Group. All rights reserved. For permission to reuse any of this content visit http://group.bmj.com/group/rights-licensing/permissions.

BMJ Case Report Fellows may re-use this article for personal use and teaching without any further permission.

Become a Fellow of BMJ Case Reports today and you can:

- Submit as many cases as you like

- Enjoy fast sympathetic peer review and rapid publication of accepted articles

- Access all the published articles

- Re-use any of the published material for personal use and teaching without further permission

For information on Institutional Fellowships contact consortiasales@bmjgroup.com

Visit casereports.bmj.com for more articles like this and to become a Fellow 